\title{
Interculturalidad: ¿Monólogo o Diálogo? Pugnas Lingüísticas y Textuales en las Reformas Educativas en América Latina
}

Denise Y. Arnold

\begin{abstract}
Resumen

The present essay perceives in the inauguration of the new Magister in Intercultural and Bilingual Education in Temuco, the initiation of a second stage of Educational Reforms in Latin America, this time with a regional rather than a global focus. In this context, the paper takes into account various criticisms of the first stage of reforms before considering new educational challenges. It questions above all the linguistic preconceptions behind the notions of "culture" and "interculturality" that are being used in current educational programmes, finding there the old debate between proponents of linguistic pragmatics and modern Saussurean linguistics. The author concludes that only a reevaluation of the constructive function of language at the heart of this debate will facilitate a new approach to two fundamental aspects of the second stage of educational reforms: interculturality and bilingual education.

El presente ensayo percibe en la inauguración del nuevo Magister en Educación Intercultural Bilingüe (EIB), en Temuco, la abertura de una segunda etapa de las Reformas Educativas en América Latina, esta vez con un enfoque más regional que global. En este contexto, el ensayo toma en cuenta varias críticas de la primera etapa de Reformas antes de considerar nuevos retos educativos. Cuestiona sobre todo las presuposiciones lingüisticas en que yacen las nociones de "cultura" $e$ "intercultura" que se usan en los programas actuales de la EIB, encontrando allí el viejo debate entre la pragmática lingüística y la lingüística saussureana moderna. La autora concluye que sólo una reevaluación de la función constructiva del lenguaje en el meollo de aquel debate, nos permitivía abordar mejor dos aspectos fundamentales de una segunda etapa de Reformas Educativas: la interculturalidad, por una parte, y la educación bilingüe, por otra.Cuando las culturas y las lenguas llegaron a animarse mutuamente, el lenguaje se tornó totalmente diferente; se alteró su propia calidad: en vez de un mundo lingüístico tolémico, unificado, singular y cerrado, surgió un universo galileano, construido de una multiplicidad de lenguas que se animaron una a otra.

M. Bajtín, 1975: 429-30 (citado en Todorov, 1984: I5).
\end{abstract}

\footnotetext{
${ }^{1}$ Birkbeck College London e ILCA, Instituto de Lengua y Cultura Aymara, La Pax, Bolivia. E-mail: ilea@ mail.megalink.com
} 


\section{Introducción}

Evidentemente, la primera etapa de las reformas educativas en países como Bolivia y Chile, consistió en propuestas en general, dirigidas a nivel transregional por expertos intemacionales en el tema, que luego se han implementado, sobre todo, desde arriba hacia abajo. En este sentido, la inauguración del Magister en Educación Intercultural Bilingüe (EIB) en la Universidad Católica de Temuco, abre una segunda etapa de estas reformas educativas: una nueva brecha dirigida - esta vez por los profesionales regionalesa las necesidades del contexto regional, en particular de la IX Región de Chile con su población mapuche, y la problemática de la relación intercultural e interlingüe entre las poblaciones mapuche-winka. Por tanto, es una oportunidad valiosa para escuchar algunas críticas de la primera etapa de reformas, recuperar lo mejor de sus experiencias y luego lanzar nuevos retos en un contexto más cercano a la realidad.

En este entendido, desarrollamos en el presente ensayo, ${ }^{2}$ algunas reflexiones sobre las nociones de "cultura" e "intercultura" desde la perspectiva del lenguaje que yacen en el fondo de muchas inquietudes de la primera etapa de las reformas, en que se ha pasado por alto la función del "lenguaje" en la construcción cultural y como vehículo de la transmisión cultural ( $y$ así de la reproducción social). Desde nuestro punto de vista, una reevaluación de esta función constructiva del lenguaje, nos permitiría abordar mejor dos aspectos fundamentales de una segunda etapa de reformas educativas: la interculturalidad, por una parte, y la educación bilingüe, por otra. Además nos permitiría vincular mejor estos dos aspectos con las prácticas cotidianas del aula.

\section{Entre la Lingüística Saussureana y la Pragmática}

En el marco de la educación bilingüe, los vínculos entre el lenguaje hablado y el escrito, las prácticas culturales y las cuestiones de la auto-identidad con lo que pasa en el aula, no son fáciles de coordinar. En Bolivia, muchos estudiosos ${ }^{3}$ han comentado que los textos producidos por la Reforma Educativa, sobre todo los módulos en Lenguas Nativas, siguen normas demasiado académicas y no tratan de la realidad de la lengua hablada a nivel cotidiano. Se hacen las mismas críticas en relación con los esquemas de formación docente en estas lenguas.

Estas tendencias nos han exigido preguntar por qué esto es así. En este caso, no estamos pensando de las razones históricas ni las políticas por estas imposiciones. Tampoco nos preocupan mucho las formas hegemónicas de la planificación lingüística estatal desde arriba que sufrimos en los países andinos, con sus formas de normalización que son en esencia historicistas y verticalistas, y que ignoran los derechos lingüísticos de los pueblos originarios e indígenas ${ }^{4}$. Lo que nos interesa aquí es precisamente las razones más profundas detrás de estas imposiciones, sobre todo las epistemologías del lenguaje que las moldean y los paradigmas lingüísticos que las gestan.

2 El presente ensayo se basa en una ponencia presentada en la inauguración del Magister en Eđucación Intercultural Bỉlingüe, organizado por cl Instituto de Estudios de la Universidad Católica de Temuco, y que se llevó a acabo cl 14 de Diciembre de 2001.

3 Ver por cjemplo Alavi (1998), Annold, Yapita y López (1999), Amold, Yapita y Sachdev (2000), Arnold, Yapita y olros (2000), CEB LAE (1999), Medina (2000, Yapita (1998) Yapu (1999), etc.

4 Ver por ejemplo Aurolyn Luykx (2001) "Diversity in the New World Order: State Language Policies and the Internationalization of Quechua". Ponencia presentada al $2^{\circ}$ Spenecr Early Career Institute in Anthropology and Education: "Globalization and Education". Chicago, II., May 10-13, 2001. 
Sospechamos que, al fondo de estas imposiciones, yace el viejo debate entre los proponentes de la pragmática (o "translingǘstica" en los términos de Bajtín) y de la lingüística saussureana moderna. Por tanto sugerimos que, para poder desarrollar los esfuerzos necesarios para revincular las prácticas culturales -e interculturales- en juego, con las prácticas discursivas y educativas de la región, primero es necesario recuperar algunos elementos teóricos y prácticos de la pragmática. Hasta el presente, los proponentes de la lingüística saussureana que indudablemente tienen mayor vigencia en la implementación de las diferentes Reformas, han podido sesgar el estudio del lenguaje bajo el filtro de la escritura, ignorando así la naturaleza de la oralidad y su propia relación con la escritura. Todos los detalles del análisis saussureano de la morfología y sintaxis del lenguaje escrito que ellos aplican, si bien son necesarios en algún momento, sin embargo nos han llevado más y más lejos de la pragmática del habla cotidiano, en que la propia unidad del estudio debería ser el discurso, concebido además en el contexto socio-cultural y político de su enunciación.

Evidentemente, las razones por haber adoptado el presente enfoque academicista y saussureano son varias, y tenemos espacio aquí para revisar sólo algunas. Para comenzar, recurrimos a las ideas de dos proponentes de la pragmática de los EE.UU., Bruce Mannheim y Dennis Tedlock, en la "Introducción" a su libro editado The Dialogic Emergence of Culture (1995). Allí, ellos plantean que, en el fondo del presente acercamiento, yace una ruptura epistemológica que ha ocurrido históricamente entre el estudio de las culturas y las lenguas en los últimos 100 años. Para ilustrar esta aserción, ellos trazan las prácticas de dos ramas de las ciencias sociales en el último siglo: la antropología (o sociología) y la lingüística. Su argumento va más o menos así: que en los fines del Siglo XIX y comienzos del XX, los científicos que hicieron etnografías, por ejemplo el germano-americano Franz Boas, también trabajaron en la recolección de "textos" nativos: narraciones, mitos, leyendas, adivinanzas y lo demás. De esta manera, el estudio de las diferentes culturas y sociedades del mundo estaba muy vinculado con el estudio de sus lenguas.

Según su argumento, este período terminó debido a las influencias de la antropología social británica sobre la antropología cultural norteamericana, especialmente la corriente del "funcionalismo" y más tarde el estructuralismo, con su tendencia de recalcar las funciones en la sociedad de las instituciones y estructuras sociales, encima de las lenguas. Esto produjo el efecto entre los antropólogos y etnógrafos de la época, de tratar lo que decían los pueblos como "ilusiones" que sólo los antropólogos pudieron revelar, con su conocimiento especializado de las funciones más importantes de las instituciones en la sociedad (Ibid.: 4-5).

Esta confrontación entre diferentes perspectivas en torno al comportamiento humano en las sociedades, resultó en una separación disciplinaria, en que algunos académicos se centraron en el estudio de las culturas y sociedades, y otros en el estudio de las lenguas en sí. Desde más o menos los años 40 hasta los años 60 del Siglo XX, esta separación entre las caras sociales y lingüísticas de las ciencias sociales aumentó más y más. Gradualmente los antropólogos trataron el estudio del lenguaje como algo expresivo de las culturas y nada más, en tanto que las demandas de los intereses del Norte exigieron un enfoque más instrumental hacia las lenguas, las culturas y sociedades, sobre todo en su zona de influencia en América Latina (Ibid.: 4-5). Esta tendencia aumentó aún más en los años 70 y 80 , con el respaldo financiero de las multilaterales y bilaterales (el Banco Mundial, UNICEF, GTZ, etc.) en el mismo enfoque 
instrumental, bajo una agenda de la educación masiva de poblaciones para borrar sistemáticamente el llamado "analfabetismo" en el mundo (Amold, Yapita y otros, 2000: Cap. 3; Arnold y Yapita, en prensa).

De esta manera se entró en otra etapa, en que los antropólogos culturales estudiaron culturas y sociedades, con vista hacia el mejor entendimiento $y$ control de éstas, en tanto que los antropólogos lingüísticos y los sociolingüistas estudiaron lenguas, igualmente con un enfoque instrumental, lo que se iba desarrollando con las teorías emergentes de la "lingüística formal". Llegó el momento en que las organizaciones como el Instituto Lingüístico del Verano, desarrollaron sus gramáticas de lenguas nativas ya separadas de cualquier contexto sociocultural y de cualquier interacción social mediante estas lenguas. Como se ve, este enfoque es ya muy distinto al anterior de la escueia de Franz Boas y sus seguidores, que basaron sus etnografías en una filología fundamentada en el estudio de textos lingüísticos (Mannheim y Tedlock, Tbid.: 5-6).

Es así que el presente enfoque lingüístico en países como Bolivia y Chile, va en la dirección de la lingüística aplicada, en que se hallan fusionadas las teorías estructuralistas de Ferdinand Saussure (sobre todo del Curso de lingüística general, 1915) con los intentos aplicados del control lingüístico. Desde dicho período en adelante, los antropólogos culturales tuvieron la tendencia de mirar a los estudios lingüísticos desde fuera, para "hablar sobre" otros procesos sociales y culturales más fundamentales. Y la lengua en sí ya es vista como nada más que una representación secundaria de otras formas sociales $y$ culturales más figurativas.

Podemos agregar a estas tendencias, otra idea implícita en muchos de los programas actuales de la Educación Intercultural Bilingüe (cuyos orígenes también se remontan a la escuela estructuralista de Saussure y, más tarde, Lévi-Strauss), en que la oralidad es considerada como un estado más "primitivo" de la lengua, y la escritura un estado más "avanzado", lo que refleja el contenido de muchas bibliografías de los cursos actuales de la EIB, sea de Diplomado o Maestría. Criticamos esta idea en el libro El rincón de las cabezas. Luchas textuales, educación y tierras en los Andes (Arnold, Yapita y otros, 2000, Cap. 1), tomando como nuestro punto de partida la crítica de esta noción de parte del filósofo francés, Jacques Derrida (sobre todo en Gramatología, 1971), y su planteamiento alternativo que la oralidad es más bien una elaboración habiada posterior que se desarrolla en base de una "escritura inerte", o "texto" (que puede tomar la forma de la escritura alfabética occidental, hojas de coca, inscripciones en roca, piel o cerámica, etc.).

Entonces llegamos a la situación en que la formación de los estudiantes en estos cursos sigue un rumbo predeterminado, en que se trata algunas materias, por ejemplo la ciencia occidental, según lo que dicen los textos escritos, en tanto que se trata otras materias centradas más en la cultura, la identidad y las lenguas nativas, según lo que dicen los comunarios del lugar, especialmente los abuelos, a nivel oral. Es más. En el segundo caso, la meta es siempre la de transformar estos dichos en "textos" escritos, ya desvinculados de cualquier contexto social, cultural, histórico o lingüístico. Según muchos estudios actuales, esto es lo que pasa a menudo en los cursos de formación en la EIB, sea en Perú, en Bolivia, en Chile o en Brasil (Paladino, 2001; Cavalcanti, 1998, etc.).

\section{Interculturalidad: ¿Monólogo o Diálogo?}

La distancia entre la realidad del habla y lo que se enseña en los cursos de la EIB es especialmente 
notoria si consideramos el trato que reciben las narraciones tradicionales en lenguas nativas (aymara, quechua o mapuzugun) en las aulas actuales. Como ya dijimos, la meta con la EIB es recopilarlas, transcribirlas (o escribirlas de memoria) y luego transformarlas en un texto escrito en la página. A veces se produce libros enteros de recopilaciones de estos cuentos — en la región aymara, éstos serían del Cóndor y el Zorro, el Zorro y la Wallata, el Zorro y la Perdiz, etc.- todos escritos como textos separados y sin alguna relación entre sí. Pero si volvemos a considerar las condiciones en que estos cuentos han sido recogidos en realidad, apreciaremos que su enunciación ha sido en una forma mucho más fragmentaria.

En nuestra experiencia, se narra estos cuentos a modo de explicar alguna moraleja, o lo que pasa tradicionalmente en un momento determinado del año agropastoril, o en algún lugar de la región, o en relación con algún personaje histórico de la misma (cf. Mannheim, 1999a; Amold y López, 2001, etc.). Este juego de diferentes voces presentes en un texto, que viene de diferentes lenguas, registros lingüísticos e instituciones culturales, es lo que Bajtín llama "heteroglosia".

Además, es muy probable que la narración en cuestión hubiera surgido como parte de un "diálogo" entre nosotros (los recolectores de los cuentos), y el o la narrador/a, lo que se podría desarrollar dentro de las propias normas culturales andinas, o si no más forzadamente, como parte de la exigencia de su curso de proveer tal texto escrito como tarea. De todos modos, hay por lo menos dos personas en aquel diálogo, además de los varios discursos institucionales (con respecto a la oralidad v. la escritura) detrás de este empeño.
El punto que quisiéramos recalcar es que, hasta ahora en los estudios lingüísticos de las reformas educativas, se ha tratado a la tradición oral como si fuera un "monólogo" cuando, en realidad, la tradición oral siempre ha sido más bien un "diálogo". La conciencia que tiene el narrador o la narradora de la presencia de su público, siempre ha sido una parte vital de la actuación, como muestran los estudios desde la obra homérica hasta las tradiciones orales actuales. Para ilustrar el mismo punto, Mannheim en otro ensayo cita al lingüista ruso, Román Jakobson (que a diferencia de muchos lingüistas también estudió la literatura), cuando narra lo que le comentó un campesino ruso:

¿Es posible contar historia sin razón alguna? No. Ingreso a la posada, charlamos, y a alguien dice "Dios no existe!" Entonces yo contesto, "Estás mintiendo, icarajo! ¿Cómo puede ser que Dios no exista?" Y le cuento una historia acerca de esto. Luego alguien agrega, "Es verdad, Dios si existe". Y yo le digo: "Ahora tú eres él que está mintiendo. ¿Dónde has visto a Dios?" Y les cuento otra historia, esta vez negando la existencia de Dios. Estoy narrando historias sólo por contradecir".

Traducción en Mannheim, 1999a:

47-8. Original en Jakobson, 1984.

Por estas razones, Jakobson y los estudiosos de la "etnografía del habla" o "de la actuación" (Mannheim, Tedlock, Hymes, Duranti, etc.), arguyen que el diálogo es una forma del habla más fundamental que el monólogo. Ellos subrayan el hecho de que rara vez hay monólogos. Aun cuando hablamos con nosotros mismos, a modo de pensar, hacemos un diálogo, ¿no es verdad? Adcmás, es más común a nivel mundial el citar directamente a otra persona en el habla que usar el discurso indirecto, p. 
ej. decimos directamente "tal persona dijo tal..." en vez de decir "según tal... habría que..."

Es igual en las narraciones aymaras. Con Juan de Dios Yapita, nos dimos cuenta que estos cuentos están organizados según las diferentes voces que intervienen en su actuación. Comienza con la voz del narrador (o la narradora), pasa a las voces de los diferentes personajes o protagonistas del cuento (el Zorro, el Cóndor, la Imilla), luego a la voz de la abuela o el abuelo que ha contado el cuento al narrador, $y$ finalmente a las voces de los antepasados que habían contado el cuento a él o ella, todas estas voces siendo marcadas oralmente por la expresión característica de este género de cuentos: ukhamaw sasaw sataw siw: "así diciendo había dicho dice" (en el aymara de Oruro). De esta manera, se construye en el cuento una trama "intertextual" de diferentes voces, organizadas en estratos del tiempo (Amold y Yapita, 1992: 207).

Esta misma estratificación de voces tiene su función pragmática en la memorización de la actuación. Por ejemplo, U. Ricardo López que trabaja con nosotros, nos llama la atención a la terminología aymara para este entrelazado de voces, en que el narrador que guía es llamado ira, y lo que le sigue es llamado arka, la misma terminología que se encuentra en muchas otras instancias culturales, por ejemplo el orden de actuación en los conjuntos de músicos, en el orden de actuación de los animales en un rebaño, etc. (Arnold, et al., 2000: 42, 56). Según esta función, si el guía no puede recordar bien un episodio determinado, entonces la intervención del seguidor le ayuda a recordar. De este modo, el trenzado del diálogo entre dos (o más) personas, es una parte fundamental de la pragmática de la enunciación (o de la música).

Esta situación no es única en los Andes. En el mismo libro de Tedlock y Mannheim, un ensayo de Jane Hill muestra que un narrador mexicano puede expresar veinte diferentes voces en un minuto de narración (Hill, 1995). En la actuación (o performance), para poder realizar esta producción y expresión de muchas voces, o categorías de voz, el narrador recurre a varias técnicas: por ejemplo a cambios en el estado emocional de un personaje, según el tono de la voz, el gesto, la entonación, un crescendo, la disfluencia, la cita directa o indirecta, etc.. En los estudios de la pragmática, Goffman ha llamado "posicionamiento" (en inglés "footing") a esta habilidad del narrador, de contextualizar los diferentes personajes en el cuento (Goffman, 1979).

En nuestro propio trabajo, recurriendo a los ejemplos previos de escritores como Tedlock, Hymes y Hornberger, hemos experimentado además con $10 \mathrm{~s}$ diferentes recursos de la escritura, tanto en aymara como en castellano, para ver hasta qué punto pudimos expresar visualmente estas diferentes voces en la página (Arnold y Yapita, 1992, 1994, 1999, etc.). En los ejempios andinos, tuvimos que tomar en cuenta además las similitudes formales entre las diferentes voces en la trama del cuento y las diferentes hebras que están copresentes en un textil, un fenómeno cultural y lingüístico que caracteriza la estructuación de muchos "textos" en la región. En este sentido, nuestra interpretación formal del texto no es arbitraria, sino sigue de cerca lo que Mannheim (1999b: 18) llama los "estímulos formales" o "estructuras formales" regionales que organizan un texto, según el marco institucional del paisaje cultural en que el texto es transmitido, y cuyos rasgos determinados guían y modifican su interpretación por el público regional. El mismo intercalado de estos otros "textos", del textil o de otras instancias de la cultura, dentro de nuestro propio texto o discurso, es también una ilustración de lo que Kristeva (1984) llama "intertextualidad". 
De esta manera, el fenómeno cultural y lingüístico de la coexistencia de varias voces en la enunciación de un cuento, simplemente hace eco de las diferentes voces que coexisten en la actividad textil. Por ejemplo, hemos mostrado cómo, en el inicio de la actividad de tejer, la tejedora entra en diálogo primero con la Tierra Virgen y luego con el espíritu del ser dentro del textil, que aún es wawa. Luego, mediante su actividad textil, la tejedora transforma gradualmente esta "wawa" en el textil, en una "persona" de su propia familia. A la vez, los distintos seres que emergen en la vida textil, desarrollan sus propias dimensiones ancestrales y corporales. Es así que las voces del textil surgen no sólo en las enunciaciones de la tejedora, sino también a través del vaivén de la trama que introduce luz y aliento en la "boca" textil, así otorgándoles vida (Arnold, Yapita y otros, 2000: Cap. 11; Arnold, 2001).

\section{La Naturaleza de la Subjetividad Lingüística}

Con estos ejemplos de la multivocalidad prevalente de la enunciación y la actuación, quisiéramos retar al enfoque lingüístico saussuriano que se enseña en la EIB, en que el actor social es percibido como un individuo que actúa como la fuente primaria del habla, tanto de langue como de parole.

Esta percepción es muy evidente, por ejemplo, en el positivismo lingüístico que construye las figuras que ilustran los textos de consulta de la lingüística saussureana y que se usan para el análisis de las situaciones del habla. En estas figuras, este actor social está claramente desvinculado del resto de la sociedad, a tal grado que su representación muchas veces es sólo en un monólogo, como "oyente" o "hablante" (y no ambos a la vez, como ocurre en la realidad), y a veces su desvinculación llega a tal extremo que se expresa su contribución a la realidad sólo en su condición de una "cabeza", con boca y orejas funcionales, pero sin el resto del cuerpo.

Según Jakobson (1953), el "monólogo" de este tipo es una forma de patologia social, cuyos orígenes ontológicos quizás se remontan al dominio del Dios judeocristiano creador, que al crear el mundo, actuó solitariamente y no necesitaba hablar con nadie. Desafortunadamente se enseña hasta ahora la lingüística saussureana en las carreras de lingüística en Bolivia y en los cursos de la Educación Intercultural Bilingüe, sin complementarla adecuadamente con la pragmática que nos enseña Jakobson, Bajtín y sus seguidores. Debido a eso, se ha otorgado una prioridad ontológica al monólogo sobre cualquier otra forma del habla, y se ha podido ignorar muchas posibilidades del uso del lenguaje en la práctica cotidiana.

Ahora, es necesario volcar nuestra atención al diálogo en vez del monólogo. Como señalan Mannheirn y Tedlock (Ibid.: 10 y sig.), una consecuencia de enfocar el dialogismo en vez del monologismo, es que la lengua o langue (en los términos de Saussure) como un sistema compartido, se convierte en una propiedad emergente de los diálogos, en vez de tener una prioridad ontológica sobre cualquier otra forma del habla. En estos contextos, los diálogos ya no constituyen una serie de monólogos juntados en secuencia, sino que éstos constituyen la propia escena de la producción de las estructuras compartidas de lengua, que pueden ser aplicadas posteriormente para el propósito de hacer un monólogo.

Por ejemplo, en cualquier ponencia académica, se suele hacer un monólogo que no espera una respuesta inmediata de la audiencia. Pero aun así, este monólogo está ya insertado en un mundo sociolingüístico en que hubo un sinnúmero de relaciones sociales anteriores entre primera, segunda, 
y tercera personas, $y$ de debates sobre las mismas cuestiones entre investigadores y entre los filósofos del lenguaje. En este sentido, el diálogo entre estas personas y los debates previos es ontológicamente previo, y el monólogo académico tiene una función posterior de resumir estos diálogos; no es al revés.

\section{Las Prácticas Sociales del Diálogo Intercultural}

En la actualidad, es común construir la relación entre sistcmas culturales y prácticas culturales basados en el mismo modelo que generó Saussure sobre el habla y la lengua, y esto es lo que hace la EIB. De esta manera, se ha percibido el origen de la expresión cultural en la enunciación de distintos actores sociales "como individuos". En vez de esto, como recalcan Mannheim y Tedlock (Ibid.: 8 y sig.), es más probable que la situación sea al revés; es decir, las culturas se reconstituyen y se revisan continuamente, mediante los diálogos entre sus miembros. En este sentido, los acontecimientos sociales ya no son la suma de todas las acciones de los participantes como individuos, cada uno de los cuales está desempeñando un papel predeterminado, sino que son escenas donde la cultura compartida emerge de la interacción social.

Ahora bien, podemos preguntarnos: ¿Cómo se puede reconocer un diálogo intercultural? y ¿Qué implicación tendría esto para un aula intercultural?. La implicación de los argumentos desarrollados hasta aquí es que, en vez del monólogo fundamentado y $\sin$ interrupción del profesor/a (a modo del Dios judeocristiano), habría que dejar el espacio para un verdadero "diálogo" entre educando y docente. Por supuesto, en este diálogo, tanto el educando como el/ la docente tendría el derecho de expresarse en su debido momento, a veces según sus propias normas culturales y a veces según las normas, impuestas, de] comportamiento en el aula. Además, en los acontecimientos con una mayor participación, se tendría que dejar el espacio para que todos los niños/ as, en su integridad, tengan la oportunidad de expresar sus propios valores culturales, en diálogo con los valores culturales del docente. Entonces, en vez del monólogo anterior en que $\mathrm{el} / \mathrm{la}$ docente se pone frente a la clase para instruirla, habría que desarrollar otro ambiente en que se pueda invitar al docente a compartir su mundo cultural con los educandos en condición de igualdad, y lo mismo vale para los educandos.

El crítico literario ruso, Mikhail Bajtín, ha considerado esta cuestión del diálogo con otras culturas. Para él, la meta no debe ser la de querer reunir material sobre el Otro, ni la de reconstruir el punto de vista del Otro y luego tratar de reduplicarlo o entrar en ello. Tampoco apoya a este proceso el retener el dogmatismo del punto de vista propio ni el volcarse hacia un relativismo extremo. Para Bajtín, cada uno de estos enfoques más bien restringen el diálogo. En lugar de éstos, habría que proceder dialógicamente, buscando un "entendimiento creativo" (vzhivanie en ruso) mediante el hecho de la "foraneidad". Según Bajtín, este sentido de foraneidad es lo que hace posible el diálogo y que a la vez nos ayuda a entender otra cultura más profundamente. Esto es porque cada cultura posee significados de los cuales no está consciente y que no se expresan en la realidad, pero que existen en un estado potencial. Sólo el diálogo revela esta potencia y le da una cualidad más tangible, aunque de una manera incompleta. Al mismo tiempo, el foráneo experimenta el mismo sentido de potencia, lo que le ayuda a entender estas potencialidades en su propia cultura. Este mismo proceso es mutuamente enriquecedor y educa a cada cultura respecto a la otra. Esto puede llegar a tal punto que el diálogo creará nuevas potencias, realizables mediante las actividades y diálogos en común de ambos grupos. Como lo 
expresa Bajtín, “...en un encuentro dialógico entre dos culturas... cada una retiene su propia unidad y totalidad abierta, pero se enriquecen mutuamente" (en Emerson and Holquist, 1986: 7, citado en Morson y Emerson, 1990: 55-56).

Una vez que apreciamos el fenómeno de "cultura" como algo que emerge de un fondo dialógico, entonces nos damos cuenta de que el proceso de la enseñanza-aprendizaje en el aula es también un fenómeno cultural/intercultural emergente, una especie de "intersubjetividad" en que el conocimiento está producido, reproducido y revisado en diálogos constantes entre docentes y educandos. En este proceso de coproducción mutua, se construye y se respeta en un momento lo propio, en otro momento el mundo del Otro, las tensiones creativas entre estas dos posibilidades prestando la energía para generar el diálogo intercultural. En este sentido, habría que repensar "cultura" (e intercultura) y la teoría cultural (e intercultural) como partes vitales de un campo de pugna, con niveles jurídicos, conceptuales y epistemológicos.

Esto es dentro del aula; pero la interculturalidad debe ir mucho más allá de esas cuatro paredes. En el libro El rincón de las cabezas (Arnold, et al., op. cit. ibid.: Cap. 4), mediante un estudio de caso en el altipiano boliviano, llegamos a reconocer que la producción cultural de la comunidad donde la escuela rural está ubicada, ha estado en marcha, mediante los diálogos y los propios discursos comunales, mucho más antes de la creación en el sitio de la misma escuela, o de la Reforma Educativa boliviana actual. Sólo al apreciar este fondo institucional, tan propio de las comunidades andinas, se puede identificar toda la multiplicidad de contribuciones, interpretaciones, opiniones y contra-opiniones, acerca de la realidad ya vigente en las comunidades, respecto a sus propios valores culturales. De la misma manera, se puede llegar a identificar toda una multiplicidad de voces que han apoyado a la construcción de la Nación en la comunidad, o la comunidad en la Nación; además, se puede apreciar las memorias comunales de otros estados andinos anteriores a la República actual (Ibid., Capítulo 7).

Estos contextos intra- e interculturales dentro de la Nación, hace aún más problemática la práctica anterior de manejar en el aula un monólogo autorizado sobre cualquier tópico. Siempre oiremos otras interpretaciones y reinterpretaciones de la función de la escuela en la comunidad (o cualquier otro tópico), dentro y fuera del aula escolar, dentro y fuera de los Institutos Normales, dentro y fuera del Ministerio de Educación. Por tanto, una pregunta muy pertinente es: ¿cómo se debe manejar estas diferencias de experiencia? ¿Mediante un monólogo o mediante un diálogo, que a veces cuestiona los mismos marcos actuales de la autoridad?

Debido a la autoridad de el/la docente y su formación como funcionario del Estado, en el contexto institucional de la escuela en la comunidad, su discurso tiene cierto peso. Pero siempre existe la posibilidad, mediante el diálogo, de que los niños podrían cuestionar esta autoridad, hasta exigir algún repensamiento de un tema determinado, en un ambiente de mundos compartidos, en que hay un perpetuo juego de creación y re-creación, negociación y re-negociación. Desde esta perspectiva, se puede reconceptualizar toda cultura como parte de un "proceso inventivo y emergente" de una "intercultura criolla" (en los términos de Clifford, 1991), en tanto que las formas lingüísticas y culturales son ejercicios en el poder y su contestación.

En este contexto, podemos reconsiderar los ejercicios actuales de la EIB de reformular las narraciones andinas (o mapuches) según el molde de textos 
predominantemente monológicos. Por una parte, podemos apreciar que estos ejercicios carecen de espíritu "intercultural", siendo más bien imposiciones monoculturales de la cultura letrada dominante, buscando transformar las narraciones andinas según normas foráneas y monológicas. Esto es sumamente evidente: por ejemplo, en las formas escriturales hispanas que se usan, las formas hispanas de prosa, de puntuación, y de cómo organizar el discurso en la página. Todo esto es parte de lo que Shiva (1993) llama la "monocultura de la mente", con sus efectos tan dañinos en todo el planeta.

\section{¿Cuándo un Diálogo no es un Diálogo?}

En este ambiente actual de "monoculturalismo" dominante, hay momentos en que se aprovecha del término "diálogo" sin mayor significación, simplemente para seguir la corriente. Entonces, ¿cómo podemos saber cuándo un diálogo es un verdadero diálogo, y cuándo es más bien un diálogo falso? Por ejemplo, en el mundo del desarrollo, el "diálogo" es un término de moda dentro de las técnicas llamadas "participativas". Tuvimos un ejemplo de este uso en el Diálogo Nacional del año 2000.

En estas ocasiones, el término diálogo puede encubrir relaciones de poder, o simplemente la transmisión de decisiones ya realizadas, desde arriba hacia abajo. Es muy común por ejemplo, la situación actual en que, para resolver cualquier conflicto entre el centro y la periferia, se ha transformado la noción derivada de Rousseau de la participación democrática de las bases para llegar a la simulación moderna de la participación, en que las decisiones ya han sido realizadas en el centro de poder, y las comunidades simplemente "simulan" su acuerdo, según una serie de gestos y categorías predeterminados. Además, un falso diálogo de este tipo puede caracterizar un momento especialmente conflictivo, cuando un grupo debe ceder ante el otro, y negociar las condiciones de su derrota.

En estas situaciones, es necesario revisar los fundamentos de la pragmática, para aclarar las definiciones actuales. Para comenzar, el sentido etimológico de "diálogo" es el habla (logos) que va como vaivén (dia), como en una conversación entre dos o más personas. Dia en este contexto tiene el sentido de "trans o inter" y no de "dos". El mismo término "diálogo" tiene también el sentido económico de un "intercambio", por ejemplo cuando se habla de un "intercambio de ideas".

Desde esta base, podemos pasar a considerar las rupturas de significado del "diálogo". El mismo Bajtín (1984: 108-12), ha considerado este problema. Él plantea, por ejemplo, que los "diálogos socráticos" no son realmente diálogos. Son formalmente diálogos, pero no funcionalmente. De esta manera, él distingue entre los diálogos anacréticos, que son formal- pero no funcionalmente diálogos, y los diálogos sincréticos, que son funcionalmente diálogos, a pesar de su forma (Mannheim y Tedlock, ibid.: 4).

Asimismo la noción de "conversación". ¿Cuándo es una verdadera conversación y cuándo es una conversación falsa? ¿Cómo vamos a definir una conversación, para tomar en cuenta estos problemas? ¿Es un género del habla o es más bien un tipo de relación entre dos o más personas? Para contestar estas preguntas, podemos recurrir a los estudios filosóficos del lenguaje, por ejemplo de H. P. Grice (1975), que ha estudiado estas cuestiones según el marco de la pragmática lingüística para llegar a la conclusión de que una conversación trata de un acuerdo ético entre dos o más personas, un esfuerzo 
de cooperación según un conjunto de propósitos en común (ver también los comentarios en Escandell Vidal, 1993).

Estas reflexiones en el marco de la pragmática intercultural, nos ayudaría a considerar otros asuntos más. Por ejemplo, podemos dejar de ocuparnos en las clases de lenguaje formulando listados de sufijos, léxico, oraciones simples o vocabularios en base a palabras sencillas, que son poco pensados y además son muy desvinculados de su contexto socio-cultural. En vez de esto, podemos desarrollar otras tareas basadas en preguntas nuevas: por ejemplo, ¿Cuáles son las características lingüísticas de la didáctica aymara en el aula? y cómo se distinguen éstas de las características de la didáctica hispana? Luego podremos poner en marcha, en la acción, los resultados de estas investigaciones.

\section{¿De la Estructura a la Acción, o de la Acción a la Estructura?}

En este sentido, hay razones éticas y políticas para seguir el camino de Jakobson y sus seguidores hacia la etnografía del habla y la expresión cotidiana de verdaderos diálogos (o textos), y verdaderas conversaciones, que representan a la vez las múltiples voces de los diferentes actores sociales, en lugar de los monólogos dominados por una voz, cerrada y dictatorial, y respaldada por el status quo.

En la práctica, como señala Mannheim y Tedlock (Ibid: 4-5), las teorías lingüísticas de Jakobson, Bajtín y sus seguidores también sugieren otra manera de apreciar la relación entre la "estructura social" y la "acción". Es común en las ciencias sociales pensar en la "acción" (prácticas, habla, actuación o parole) como un resultado de la estructura social (institución, intención, competencia o langue) que la ha generado.
En cambio, la intuición de Bajtín de que cada palabra "ya tiene el sabor del contexto y los contextos en que ha vivido su vida social", reconoce así que cada concepto o escena ya está situado en un momento socio-histórico-político determinado. Según este modelo, la acción no resulta de la estructura predeterminada; más bien la estructura emerge de la acción social concertada. En este sentido, las palabras son "apropiadas" por individuos, pero no "inventadas" por ellos.

Tampoco podemos seguir conceptualizando el individuo como "el autor y la autoridad" de un texto. Más bien, habría que apreciar con Tediock y Mannheim, la subjetividad en sí como una "constelación de muchas voces" (Ibid.: 8). En estas nuevas reflexiones sobre una subjetividad multivocal, vale la pena considerar que cada uno de nosotros lleva encarnada la memoria de todas las voces de nuestros antepasados, además de las conferencias a que hemos asistido, los libros y poesías que hemos leído, y las conversaciones con los miembros familiares y amigos con quienes hemos charlado a lo largo de la vida. Y, aún más allá de estas generaciones inmediatas, las células de nuestro cuerpo son construidas como consecuencia de millones de años de evolución, y de muchas especies (no sólo lo humano, sino lo bacterial, viral, etc.). En este contexto, la posibilidad del surgimiento de la cultura ya inminente en cada uno de nosotros, sólo se pone en existencia a través de nuestras interacciones sociales mediante el uso del lenguaje. De igual modo, no tenemos otra alternativa que interactuar con otros mediante el lenguaje, para poder participar en otras culturas, interculturalmente.

Expresado de otro modo, y retornando al debate que planteamos inicialmente, no se puede separar el estudio de la cultura o la sociedad, del estudio del lenguaje. Y no se puede entender una cultura o una sociedad sin entender sus interacciones lingüísticas. 
Este hecho exige del profesor/a, en un ambiente intercultural, el saber por lo menos algo del lenguaje de la otra cultura con que está en contacto. Exige de! profesor/a también la habilidad de interiorizarse de la experiencia "sensible" y "visceral" de otras culturas, para poder traducirlo en el contexto intercultural del aula. No es suficiente recurrir a un diccionario para llegar a una aproximación del sentido de una palabra aymara, menos todavía un diccionario con definiciones simples y "mono"-contextuales, lo que tiende a favorecer la Reforma. Más bien hay que "dejar que las palabras entren en su sangre y luego soltarlas de nuevo" en los términos de Walter Benjamin. Como decían Bajtín y además Vygotsky (1962: 146), hay una diferencia fundamental entre el "sentido" de una palabra, que es "la suma de todos los acontecimientos psicológicos despertados en nuestra conciencia de la palabra", y su "significado" según un diccionario, con mucho menos alcance (ver también Volosinov, 1973: 101). En lo ideal, habría que sentir la misma experiencia en su propia sangre, para poder compartirlo interculturalmente.

Es importante también la contribución del docente en el aula de sus propias comparaciones lingüísticas, por ejemplo entre el uso del aymara y del castellano, para expresar ciertos conceptos. A nuestro modo de entender, esta contribución intercultural ha sido despreciada en los últimos años por aquellos que insisten en imponer los mono-universalismos del lenguaje que acompañan, por ejemplo, la enseñanza del inglés como segunda lengua, sin tomar en cuenta las condiciones del aula boliviano.

Es necesario también que los/las docentes tengan un manejo básico de las epistemologías comparadas en juego en los debates que pueden surgir en torno a las diferentes nociones de la ciencia o del arte, para no caer simplemente en respuestas según un relativismo extremo o un dogmatismo tajante. Igualmente, debemos tomar en cuenta las dimensiones históricas y lingüísticas de estos debates, y las enunciaciones del pasado, tanto a nivel regional como global, para entender la contextualización de las relaciones interétnicas en cualquier momento determinado.

\section{Los Límites entre el Mismo y el Otro}

Si proponemos que el lenguaje y la cultura son, ambos, dialógicos en sus fundamentos, entonces debemos reubicarlos en los intersticios entre las personas (como sugirió Geertz en otro contexto). En este entendido, el lenguaje y la cultura como cualidades emergentes de la acción social, son el resultado de millones de diálogos profundos que han influido en las vidas y las energías corporales de los diferentes participantes en un momento histórico determinado.

En este contexto, el diálogo tiene un sentido ontológico. No es necesario que los patrones lingüísticos, culturales y sociales se generen nuevamente con cada interacción social. En vez de esto, cada interacción ocurre dentro de los coordinados de instituciones sociales e históricas específicas, que influyen en la interacción, en tanto que están reformadas por la interacción específica. Un ejemplo cotidiano de este fenómeno ocurre en cualquier conversación en la calle, en que intervengan en el acontecimiento no sólo los participantes directos sino también los observadores, con su mirada, actitud, su postura corporal, sincronización rítmica, comentarios, etc.

Es igual en el aula: aunque el/la docente en su estilo didáctico presenta poco más que un monólogo, sin embargo todos los presentes están participando por su presencia institucional en el acontecimiento. Y si se expande el evento para incluir un diálogo entre 
docente y alumnos, entonces habría aún más sentido de participación en el evento. Y si expandimos el contexto aún más para abarcar un verdadero diálogo intercultural en el aula, entonces se traspasaría no sólo las normas convencionales del diálogo, sino también de culturas. "La lengua" dijo Bajtín "yace en el límite entre uno mismo y otros". En este sentico, la lengua tiene una cualidad emergente. Como observan Mannheim y Tedlock, se produce entre los hablantes, pero a la vez la comunicación entre ellos incorpora algo que es independiente de ellos. Debido a esta posibilidad, las culturas y las lenguas adquieren regularidades mediante la interacción de individuos, sin estar limitado a sólo estos individuos.

Debido a este fenómeno, Mannheim, basánđose en Jakobson, concluye que la verdadera "gramática" de las culturas no-letradas, por ejemplo las andinas, es la poesía o el canto, como el medio por cual las poblaciones colectivamente acuerdan entre sus estilos de habla, las versiones de las narraciones que predominan, y sus interpretaciones, todo según una "cultura del conocimiento" muy difundida en la sociedad (Mannheim, 1986). Este fenómeno es muy distinto a las gramáticas formales desarrolladas hasta ahora por la EIB, que están arrancadas de sus contextos socio-culturales y que imponen determinadas formas lingüísticas sobre otras, determinadas normas de estandarización sobre otras, y determinados modos de escribir sobre otros, todo según las ideas monológicas de un sistema incontestable de autoridad.

\section{Conclusiones}

Estas últimas reflexiones sobre la naturaleza de una gramática dialógica, cuestionan al fondo las tendencias actuales de hablar del patrimonio cultural como si fuera algo fijo y estático. Cuestiona también la noción de cultura, o intercultura, como si fuesen "estados mentales", conjuntos de creencias y costumbres, o la adopción de actitudes liberales hacia el estado actual de las cosas, como si se pudiera aprovechar esta nueva actitud para participar simultáneamente en dos culturas preexistentes.

Más cerca a la realidad, según lo que nos enseña la pragmática lingüística, es que la interculturalidad describe más bien una dinámica incesante entre dos culturas en un estado perpetuo de flujo y desenvolvimiento. Además estas dos culturas, aunque creadas por individuos, existen aparte de estos individuos, en su propio espacio ontológico. Por tanto, al participar como individuos en la interculturalidad, estamos participando en este estado de flujo, y no en cosas predeterminadas. La negociación incesante de "posición" o "posicionamiento" (en los términos de Goffman), de crear un espacio político para expresarnos y conde nuestras ideas tienen plena vigencia, de poder considerar interculturalmente la propia historia de una cultura relativa a la otra, de comparar diferentes maneras de hacer las cosas, son todas parte de esta dinámica de la interculturalidad.

Esto es por que, una verdadera interculturalidad, en su desenvolvimiento, nos exigiría abrir las puertas de la universidad hacia la comunidad, para que los comunitarios, padres de familia, docentes y educandos participen plenamente en su construcción y transformación. 


\section{Bibliografía}

ALAVI, Zacarías (1998) "Los textos escolares y la calidad lectora en el contexto de la educación intercultural bilingüe de la Reforma Educativa”. En: XII Reunión Anual de Etnología, 26 al 29 de Agosto de 1998, Tomo II, pp. 443-455. La Paz: MUSEF.

ARNOLD, Denise Y. (2001) “ 'Convertirse en persona' el tejido: la terminología aymara de un cuerpo textil", en (ed.) Victoria Solanilla D., Actas de la I Jornada Internacional sobre Textiles Precolombinos, pp. 9-28. Barcelona: Universitat Autònoma de Barcelona.

ARNOLD, Denise Y. y U. R. LÓPEZ G. (2001) “Jukumarinti sawurinti: EL oso-guerrero y la tejedora, Un repertorio literario de to masculino y lo femenino en los Andes". En: Ciencia y Cultura. Revista de la Universidad Católica Boliviana San Pablo. No. 9. Julio del año 2001, pp. 13-42.

ARNOLD, Denise Y. y Juan de Dios YAPITA (1992) "Sallqa: dirigirse a las bestias silvestres en los Andes meridionales": En: Arnold (Comp). Hacia un orden andino de las cosas, pp. 175-212. La Paz: Hisbol e ILCA.

(1994) (Eds.) Jichha nä parlt'ä. Ahora les voy a narrar, por Elvira Espejo. La Paz: UNICEF, ILCA y Casa de Las Américas.

(1999) "Las canciones a los animales en un ayllu andino. Hacia la arquitectónica textil de un texto oral", en (comp.) Juan Carlos Godenzzi A., Tradición oral andina y amazónica. Métodos de análisis e interpretación de textos, pp. 229-271. Cusco: Bartolomé de Las Casas.

(En prensa) "The Nature of Indigenous Literatures in the Andes: Aymara, Quechua and Others". En: (Eds.) M. J. Valdés y Djelal Kadir, Latin American Literatures: A Comparative History of Cultural Formations, Vol. 3. The Presence of Indigenous Cultures. Oxford: OUP.

ARNOLD, D. Y., Juan de Dios YAPITA y U. Ricardo LÓPEZ G. (1999) "Graves fallas a la vista. Leer y escribir en aymara bajo la Reforma". En: T'inkasos, revista boliviana de ciencias sociales No. 3, Abril de 1999: 103-115.

ARNOLD, D. Y., Juan de Dios YAPITA y otros (2000). El rincón de las cabezas. Luchas textuales, educación y tierras en los Andes. La Paz: UMSA e ILCA.
ARNOLD, D. Y., Juan de Dios YAPITA e Itesh SACHDEV (2000). "Re-voicing identity in the language of schooling in Bolivia: emerging demands for language planning from the "bottom up". A ser publicado en los Procedimientos de la Conferencia Internacional sobre los Asuntos de la Ciudadanía Social en la Integración Pan-Americana, que se llevó a cabo en Ottawa, Canadá, 9 a 10 de Marzo de 2001.

BAJTíN, M. M. (1975) Originalmente en "Iz predystorii romannogo slova". En: Voprosy literatury i éstetiki. Moscow, 1975, y luego traducido al inglés en "From the Prehistory of Novelistic Discourse" en (ed.) Michael Holquist, The Dialogic Imagination. Austin, University of Texas Press, 1981.

(1984) Problems of Dostoevsky's Poetics. Editado y traducido por C. Emerson. Minneapolis: University of Minneosta Press.

CAVALCANTI, Ricardo A da S. (1998) Presente de branco, presente de grego? Escola e escrita em comuniades indígenas do Brasil. Disertación de maestría presentada al Programa de Postgrado en Antropología Social, Museu Nacional, Universidad Federal do Rio de Janeiro.

CEBIAE (1999) Interculturalidad y calidad de los aprendizajes en ámbitos urbanos. Serie: Materiales de discusión. La Paz: CEBIAE.

CLIFFORD, James (1991) "Sobre la autoridad etnográfica". En: (Comp.) Carlos Reynoso, El surgimiento de la antropología postmoderna, pp. 141-170. México: Gedisa.

DERRIDA, Jacques (1971) De la gramatología. Buenos Aires: Siglo XXI Argentina Editores.

EMERSON, Caryl y M. HOLQUIST, eds. (1986) M. M. Bakhtin, Speech Genres and Other Late Essays, p. 7 Trad. Vern W. McGee. Ver el ensayo de Bakjtín "Response to a Question from the Novyi mir Editorial Staff”. Austin: University of Texas Press.

ESCANDELL VIDAL, M. Victoria (1993) "Capítulo 5, Grice y el principio de cooperación". En: Introducción a la pragmática, pp. 91-107. Barcelona: Editorial del Hombre.

GOFFMAN, Erving (1979) "Footing", en Semiotica 25, 1/2, 1979: 1-29.

GRICE, H. Paul (1991 [1975]) Lógica y conversación. Trad. por Juan José Acero. En: Luis Ml. Valdés Villanuvea (ed.) La búsqueda de significado. Lecturas de filosofía del lenguaje, pp. 511-530 Madrid: Editorial Tecnos. 
HILL, Jane (1995) "The Voices of Don Gabriel: Responsibility' and Self in a Modern Mexicano Narrative", en (eds.) D. Tedlock y B. Mannhcim, The Dialogic Emergence of Culture, pp. 97-147. Urbana and Chicago: University of Illinois Press.

HOLQUIST, Michael, ed. (1981) The Dialogic Imagination. Trad. C. Emerson y M. Holquist. Austin: University of Texas Press.

JAKOBSON, Roman (1953) “Discussion in Claude LéviStrauss, Roman Jakobson, Carl F. Vogelin and Thomas A. Sebeok," Results of the Conference of Anthropologists and Linguists. En: International Journal of American Linguistics Mernoir 8: 11-21.

- (1984) "La théorie saussurienne en retrospection". En: Linguistics 22: 161-196.

KRISTEVA, Julia (1984) Revolution in poetic language. Trad. Margaret Walker. New York: Columbia University Press.

MANNHEIM, Brucc (1986) "Popular song and popular grammar, poetry and metalanguage". En: Word, Vol. 37, Nos. 1-2, Abril-Agosto, 1986: 45-75.

-(1999a) "Hacia una mitografía andina", cn (comp.) Juan Carlos Godenzzi A., Tadición oral andina y amazónica. Métodos de análisis e interpretación de textos, pp. 47-79. Cusco: Bartolomé de Las Casas.

- (1999b) "El arado del tiempo: Poética quechua y formación nacional", en Revista Andina (Cusco) No. 1, Julio de 1999: 1563.

MANNHEIM, Bruce y Dennis TEDLOCK (1995) "Introduction", en (eds.) D. Tedlock y B. Mannheim, The Dialogic Emergence of Culturc. Urbana and Chicago: University of Illinois Press.

MEDINA, Javier (2000) Diálogo de sordos. Occidente e indianidad. Una aproximación conceptual a la educación intercultural y bilingüc en Bolivia. La Paz: CEBIAE.

MORSON, Gary Saul y Caryl EMERSON (1990) Mikhail Bakhtin. Creation of a Prosaics. Stanford: Stanford University Press.

PALADINO, Mariana (2001) Educação escolar indígena no Brăsil contemporâneo: entre a "rcvitalizaçāo cultural" c la "desintegração do modo de ser tradicional". Disertación de maestría presentada al Programa de Postgrado en Antropología Socia!, Museu Nacional, Universidad Federal do Rio de Janciro.

SHIVA, Vandana (1993) Monocultures of the Mind. Perspectives on Biodiversity and Biotechnology. London and New York: Zed Books.

TODOROV, Tzvetan (1984) Mikhail Bakhtin. The Dialogical Principle. Trad. Wlad Godzich. Manchester: University of Manchester Press.

VOLOSINOY V.N. (1973) Marxism and the Philosophy of Languagc. Trad. de Ladislay Matejka y I. R,, Titunik. Studies in Language Vol. 1. New York.

VYGOTSKI, L. S., (1962) Thought and Language. Edicion y traducción de Eugenia Hauffmann y Gertrude Vakar. Cambridge, Mass,

YAPITA, Juan de Dios (1998) "Comentario lingüístico de los módulos cn aymara de la Reforma Educativa". En: XII Reunión Anual de Etnología, 26 al 29 de Agosto de 1998, Tomo II, pp. 459-476. La Paz: MUSEF.

YAPU, Mario (1999) "Balance desde las aulas, La Reforma y la enscr̃anza de la lecto-escritura en el campo". En: T'inkasos, revista boliviana de ciencias sociales, Agosto de 1999: 55-91. 